\title{
Driving Cessation in Patients Attending a Young-Onset Dementia Clinic: A Retrospective Cohort Study
}

\author{
Latha Velayudhan ${ }^{a, b}$ Sarah Baillon ${ }^{b, c}$ Gabriela Urbaskova ${ }^{a}$ \\ Laura McCulloch $^{b}$ Samuel Tromans ${ }^{c}$ Mathew Storey ${ }^{b}$ \\ James Lindesay ${ }^{b}$ Sagnik Bhattacharyya ${ }^{a}$ \\ anstitute of Psychiatry, Psychology and Neurosciences, King's College London, London, \\ UK; ${ }^{b}$ Psychiatry for the Elderly, Department of Health Sciences, University of Leicester, \\ Leicester, UK; ${ }^{C}$ Mental Health Services for Older People, Leicestershire Partnership NHS \\ Trust, Leicester, UK
}

\author{
Keywords \\ Young-onset dementia · Driving cessation · Cognition · Gender
}

\begin{abstract}
Background: Although driving by persons with dementia is an important public health concern, little is known about driving cessation in younger people with dementia. We aimed to determine the prevalence and factors affecting driving cessation in individuals with and without dementia aged under 65 years attending a memory clinic in a European setting. Methods: Subjects were consecutive patients assessed at a specialist memory service at a university teaching hospital between 2000 and 2010. The data collected included demographic, clinical, standardized cognitive assessments as well as information on driving. Dementia diagnosis was made using ICD-10 criteria. Results: Of the 225 people who were or had been drivers, $32 / 79$ (41\%) with young-onset dementia (YOD) stopped driving compared to 25/146 (17\%) patients who had cognitive impairment due to other causes. Women were more likely to cease driving and voluntarily than men $(p<0.001)$. Diagnosis of YOD was associated with driving cessation $(1.193,95 \% \mathrm{Cl} 0.570-1.815, p \leq 0.001)$, and was mediated by impairment in praxis with the highest indirect mediation effect $(0.754,95 \% \mathrm{Cl} 0.183-1.401, p=0.009)$. Conclusions: YOD diagnosis, female gender, and impairment in praxis have a higher probability for driving cessation in those under 65 years of age with cognitive impairment.
\end{abstract}




\section{Introduction}

Driving is an important instrumental activity of daily living and the preferred mode of transport for many adults [1], requiring the coordinated engagement of multiple cognitive and motor processes, in particular visuospatial skills, executive function, memory, attention and motor skills. Dementia is associated with a progressive decline across a number of cognitive domains [2] including those that are critical for driving. Hence, it is not surprising that driving impairments are well known in those with dementia [2-5]. Most studies to date have focused on driving performance and driving cessation in later life and late-onset dementias [6-8]. A retrospective study of 430 elderly patients at a memory clinic reported older age, living outside the city, poorer cognition and functional levels as predictive of driving cessation [7]. In another prospective study of 53 elderly men with dementia, baseline lower Mini-Mental State Examination (MMSE) scores and older age predicted driving cessation over the next 2-3 years [9].

There is increasing recognition that presentation with dementia is not uncommon in people under the age of 65, also known as young-onset dementia (YOD). While the Alzheimer's Society estimates that there are approximately 42,000 people with YOD in the UK (Alzheimer's Society statistics 2014), this is more likely an underestimate and the actual numbers may increase [10] with increasing awareness and recognition. While the effects of a diagnosis of dementia can be devastating at any age, perhaps the consequences are often more keenly felt when this happens in younger people in terms of the effects on the family and the individual [11], particularly because of the various roles/responsibilities that the person under 65 may still be expected to be undertaking. Hence, restriction of mobility and independence as a result of impairment in driving ability or driving cessation consequent to a dementia diagnosis may have a considerably greater impact in a person under 65. However, a literature search using Medline, Embase and PsychInfo databases revealed no published studies on driving cessation in YOD. Hence, the principal objective of the present study was to investigate the prevalence of driving cessation in younger people with dementia in a specialist clinic-based sample compared to individuals presenting with memory complaints, but without a dementia diagnosis. A secondary objective was to investigate whether impairments in specific cognitive domains mediate the association between dementia and driving cessation in younger people.

\section{Methods}

\section{Design, Subjects, and Setting}

This cross-sectional study included retrospective data of patients aged less than 65 years who were assessed at the Younger Person's Memory Service (YPMS) within the Mental Health Service for Older People at the Leicestershire Partnership National Health Service (NHS) Trust between January 2000 and December 2010. They were referred by general practitioners from primary care and also specialists such as neurologists and general adult psychiatrists from the secondary care, within Leicestershire and Rutland, East Midlands, England. YPMS, a specialist memory clinic for younger adults, served a catchment population of around 323,400 residents aged between 30 and 64 years as per ONS 2001 (https://www.nomisweb. co.uk/query/select/getdatasetbytheme.asp?opt=3\&theme=\&subgrp=). The study was approved by the local National Health Service Research Committee.

As part of their routine assessment, all patients had a multidisciplinary assessment by a team of a community psychiatric nurse, an occupational therapist, a psychologist, and a psychiatrist. The patients were assessed for cognitive functions, functional abilities and 
behavioural symptoms in a 90-min semi-structured interview. Everyone had neuroimaging, i.e., magnetic resonance imaging/computed tomography/single-photon emission computed tomography scan as appropriate, according to the local NHS dementia assessment protocol, used as part of routine clinical practice to assist diagnosis. At the end of the assessment, the multidisciplinary team led by a senior psychiatrist met to arrive at a consensus diagnosis. A standardized diagnosis for dementia was made according to ICD-10 criteria [12]. Cognitive testing was done using the MMSE and Cambridge Cognition Examination (CAMCOG) part of the Cambridge Mental Disorders of the Elderly Examination [13, 14].

Information on driving cessation was obtained from the patients, their carer or family. Those with driving information at the initial assessment were categorized into "still driving" and "ceased driving" (self-imposed or advised by a clinician). People with no information and those who had never driven were excluded from the analysis.

\section{Statistical Analysis}

Statistical analysis was done using IBM SPSS Statistics Version 22. An $\alpha$ level of 0.05 for statistical significance was used for all tests unless otherwise stated. Missing values for cognitive measures were imputed with mean values for each gender group for the relevant measures.

Means and SDs for continuous variables (age and cognitive measures) and frequencies and percentages for categorical variables (gender, diagnosis) were estimated.

The main exposure of interest was driving cessation. As a first step, we carried out exploratory analyses ( $t$ tests for continuous and $\chi^{2}$ tests for categorical variables) to test the association between driving status and sociodemographic (age, gender), diagnosis and cognitive measures (MMSE, CAMCOG total and CAMCOG subscale scores). Variables that were significantly associated with driving cessation on simple analyses were then entered as potential covariates in multivariable regression analyses. Binary logistic regression analysis was used to test the association between driving status as dependent variable and age, gender, diagnosis, and cognitive measures as independent variables (model 1, Table 1).

As a next step, we investigated deficits in which cognitive domains (as indexed by CAMCOG subscale scores) may mediate the association between YOD diagnosis and driving cessation. First, we carried out separate regression analyses (following the approach suggested by Baron and Kenny [15]) to test for association between the independent variable (YOD diagnosis) and potential mediator variables (CAMCOG subscale scores) and between the potential mediator variables (CAMCOG subscale scores) and the dependent variable (driving cessation; model 2, Table 1 ). Of the 11 cognitive domains measured by CAMCOG, only those that were associated with driving cessation either in the whole group or only in the YOD group of patients were then entered as mediators in the final logistic regression model to test for mediation. We employed the PROCESS macro $[16,17]$ for SPSS to test whether comprehension, remote memory and praxis scores significantly mediated the association between YOD diagnosis and driving cessation.

\section{Results}

Of the 531 subjects who attended the YPMS between January 2000 and December 2010, 246 patients provided information on driving. 21 had never driven, 168 were still driving, and 57 had stopped driving. Of the 225 drivers, 79 patients (35\%) were diagnosed with YOD. 75\% of those with YOD were diagnosed with Alzheimer disease, 11\% with vascular dementia, 5\% with mixed vascular and Alzheimer-type dementia, 5\% with frontotemporal dementia, 3\% with Lewy body dementia, and 1\% with unspecified dementia. Of the 146 patients who had 
Velayudhan et al.: Driving Cessation in Young-Onset Dementia

Table 1. Multivariable logistic regression analyses to identify predictors associated with driving cessation (model 1) and cognitive domains (CAMCOG subscales) that may be potential mediators for the association between young-onset dementia (YOD) diagnosis and driving cessation (model 2)

\begin{tabular}{|c|c|c|c|c|}
\hline & $\begin{array}{l}\text { Whole group } \\
\text { OR (95\% CI) }\end{array}$ & $p$ value & $\begin{array}{l}\text { YOD group } \\
\text { OR }(95 \% \mathrm{CI})\end{array}$ & $p$ value \\
\hline \multicolumn{5}{|l|}{ Model 1} \\
\hline YOD diagnosis & 3.52 (1.871 to 6.629$)$ & $<0.001^{* *}$ & $\mathrm{~N} / \mathrm{A}$ & \\
\hline Gender & 1.83 (0.972 to 3.459$)$ & 0.061 & $3.38(1.204$ to 9.460$)$ & $0.021^{*}$ \\
\hline Age (years) & $1.00(0.951$ to 1.052$)$ & 0.9960 & $1.09(0.984$ to 1.216$)$ & 0.096 \\
\hline Education years & 1.07 (0.958 to 1.192$)$ & 0.232 & $1.18(0.960$ to 1.455$)$ & 0.116 \\
\hline MMSE & $1.01(0.948$ to 1.066$)$ & 0.854 & $0.99(0.849$ to 1.174$)$ & 0.983 \\
\hline Total CAMCOG & 1.05 (1.029 to 1.071$)$ & $<0.001^{* *}$ & 1.03 (1.001 to 1.067$)$ & $0.042^{*}$ \\
\hline \multicolumn{5}{|c|}{ Model 2 (to assess the association between potential mediator variables and driving cessation) } \\
\hline \multicolumn{5}{|l|}{ CAMCOG subscale scores } \\
\hline Orientation & 1.08 (0.822 to 1.427$)$ & 0.569 & $1.10(0.792$ to 1.540$)$ & 0.560 \\
\hline Comprehension & 0.58 (0.374 to 0.898$)$ & $0.015^{*}$ & $0.61(0.371$ to 1.013$)$ & 0.056 \\
\hline Expression & $1.11(0.926$ to 1.329$)$ & 0.259 & $1.05(0.780$ to 1.410$)$ & 0.751 \\
\hline Recent memory & $0.76(0.463$ to 1.253$)$ & 0.284 & $0.74(0.393$ to 1.377$)$ & 0.337 \\
\hline Remote memory & 1.25 (0.992 to 1.577$)$ & 0.059 & 1.46 (1.041 to 2.049$)$ & $0.028^{*}$ \\
\hline Learning memory & $1.09(0.985$ to 1.211$)$ & 0.094 & $1.14(0.969$ to 1.337$)$ & 0.114 \\
\hline Attention and calculation & $1.02(0.815$ to 1.288$)$ & 0.837 & $0.89(0.638$ to 1.233$)$ & 0.475 \\
\hline Praxis & 1.34 (1.100 to 1.625$)$ & $0.004^{* *}$ & 1.31 (1.032 to 1.661$)$ & $0.027^{*}$ \\
\hline Abstract thinking & $1.02(0.798$ to 1.311$)$ & 0.856 & $0.88(0.632$ to 1.218$)$ & 0.435 \\
\hline Perception & $1.21(0.945$ to 1.553$)$ & 0.131 & $1.19(0.852$ to 1.672$)$ & 0.302 \\
\hline Executive function & $0.97(0.921$ to 1.016$)$ & 0.186 & $0.97(0.766$ to 1.217$)$ & $0.767)$ \\
\hline \multicolumn{5}{|c|}{$\begin{array}{l}\text { Model } 1 \text { included driving cessation as the dependent variable, YOD diagnosis as the predictor of interest, and } \\
\text { gender, age, education, MMSE and total CAMCOG score as covariates in a multivariable logistic regression model. } \\
\text { Model } 2 \text { included driving cessation as the dependent variable and the different cognitive domains (CAMCOG } \\
\text { subscale scores) as predictors in a multivariable logistic regression model. OR, odds ratio; CI, confidence interval; } \\
\text { MMSE, Mini-Mental State Examination; CAMCOG, Cambridge Cognition Examination. }{ }^{*} p<0.05 \text {; } * *<<0.01 \text {. }\end{array}$} \\
\hline
\end{tabular}

no dementia and cognitive impairment due to other causes (CIOC), 57 patients had subjective cognitive impairment, 19 had mild cognitive impairment, 46 patients had mental health diagnosis (mostly mood and anxiety disorders), and 24 had neurological disorders. The sociodemographic details for the groups are reported in Table 2. There were 6 missing values for MMSE, 55 for total CAMCOG, and 60 for CAMCOG subscores. The CAMCOG was not completed in patients for reasons such as refusal to do so, speech difficulties, and being non-fluent in English. Sensitivity analysis was carried out to compare the missing individuals with those providing data and we found that those with driving data were slightly older and mostly men but that they did not differ in their cognitive measures (online suppl. Table 1; for all online suppl. material, see www.karger.com/doi/10.1159/000488237).

Of the 225 patients who were current or past drivers (55.9 \pm 8 years and $39 \%$ women), 57 patients stopped driving, of whom 44 ( 24 women and 20 men) stopped driving voluntarily and 13 ( 4 women and 9 men) were advised to do so by a clinician via notification to the DVLA (Driver and Vehicle Licencing Agency), UK. Within the YOD group, 40.5\% (32/79) stopped driving and most of them did so voluntarily $27 / 32$ (17 women, 10 men). In comparison, only 25/146 patients with CIOC ceased to drive.

For the YOD subgroup, there was no association of driving cessation with history of head injury $\left(p=0.345, \chi^{2}(1)=2.13\right)$, alcohol use $\left(p=0.253, \chi^{2}(1)=5.36\right)$, current smoking $(0.658$ $\left.\chi^{2}(1)=3.27\right)$, presence of depressive symptoms $\left(p=0.82, \chi^{2}(1)=0.05\right)$ or anxiety symptoms $\left(p=0.44, \chi^{2}(1)=0.61\right)$. Similarly, for the CIOC cohort, there was no association of driving 
Table 2. Comparison of sociodemographic and cognitive variables between patients who stopped driving and those who are currently driving for the whole cohort and the group of patients with young-onset dementia (YOD)

\begin{tabular}{|c|c|c|c|c|c|c|}
\hline & \multicolumn{3}{|l|}{ Whole group } & \multicolumn{3}{|l|}{ YOD } \\
\hline & $\begin{array}{l}\text { stopped } \\
\text { driving } \\
(n=57)\end{array}$ & $\begin{array}{l}\text { continue } \\
\text { to drive } \\
(n=168)\end{array}$ & $p$ value & $\begin{array}{l}\text { stopped } \\
\text { driving } \\
(n=32)\end{array}$ & $\begin{array}{l}\text { continue } \\
\text { to drive } \\
(n=47)\end{array}$ & $p$ value \\
\hline Gender (female) & $29(50.9 \%)$ & $28(16.7 \%)$ & 0.073 & $19(59.4 \%)$ & $12(25.5 \%)$ & $<0.001$ \\
\hline Age, years & $56.9(7.4)$ & $55.6(7.66)$ & 0.253 & $58.4(5.3)$ & $60.2(3.6)$ & 0.091 \\
\hline Education, years & $12.3(2.9)$ & $13.2(3.17)$ & 0.072 & $11.5(2.8)$ & $13.4(2.9)$ & 0.004 \\
\hline Married/with partner & $45(78.9 \%)$ & $134(79.8 \%)$ & 0.448 & & & \\
\hline \multicolumn{7}{|l|}{ Diagnosis } \\
\hline (YOD:non-YOD) & $32: 25$ & $47: 121$ & $<0.001$ & $\mathrm{~N} / \mathrm{A}$ & $\mathrm{N} / \mathrm{A}$ & $\mathrm{N} / \mathrm{A}$ \\
\hline MMSE & $23.7(11.6)$ & $26.23(4.6)$ & 0.021 & $19.1(4.9)$ & $22.1(5.7)$ & 0.019 \\
\hline Total CAMCOG & $75.2(18.8)$ & $87.48(12.8)$ & $<0.001$ & $64.8(16.9)$ & $75.3(15.7)$ & 0.006 \\
\hline \multicolumn{7}{|l|}{ CAMCOG subscores } \\
\hline Orientation & $7.9(2.6)$ & $9.2(1.8)$ & $<0.001$ & $6.5(2.2)$ & $7.7(2.5)$ & 0.030 \\
\hline Comprehension & $8.4(1.2)$ & $8.6(1.1)$ & 0.108 & $7.8(1.2)$ & $7.8(1.3)$ & 0.989 \\
\hline Expression & $16.9(3.3)$ & $17.8(2.5)$ & $<0.001$ & $15.2(2.9)$ & $16.1(3.1)$ & 0.185 \\
\hline Remote memory & $3.4(1.6)$ & $4.3(1.6)$ & $<0.001$ & $2.7(1.3)$ & $3.7(1.7)$ & 0.005 \\
\hline Recent memory & $3.4(1.1)$ & $3.7(0.9)$ & 0.031 & $2.9(0.9)$ & $3.1(1.1)$ & 0.447 \\
\hline Learning memory & $9.7(4.3)$ & $11.8(3.6)$ & $<0.001$ & $7.0(3.6)$ & $9.3(3.8)$ & 0.009 \\
\hline \multicolumn{7}{|l|}{ Attention and } \\
\hline calculation & $6.4(2.9)$ & $7.6(2.3)$ & 0.001 & $4.7(2.7)$ & $5.6(2.8)$ & 0.158 \\
\hline Praxis & 9.7 (2.9) & $11.3(1.9)$ & $<0.001$ & $8.2(2.8)$ & $9.7(2.4)$ & 0.013 \\
\hline Abstract thinking & $5.8(2.2)$ & $6.5(1.9)$ & 0.014 & $4.9(2.1)$ & $4.9(2.1)$ & 0.832 \\
\hline Perception & $7.3(1.7)$ & $8.1(1.2)$ & $<0.001$ & $6.8(1.7)$ & $7.5(1.4)$ & 0.046 \\
\hline Executive functions & $16.9(12.3)$ & $18.2(5.4)$ & 0.288 & $12.8(4.4)$ & $13.6(4.9)$ & 0.509 \\
\hline
\end{tabular}

Values are mean (SD) or $n(\%)$. MMSE, Mini-Mental State Examination; CAMCOG, Cambridge Cognition Examination subscales that may be potential mediators for the association between young-onset dementia (YOD) diagnosis and driving cessation (model 2).

Fig. 1. This figure shows that the total effect of young-onset dementia (YOD) diagnosis on driving cessation is mediated partly through certain cognitive deficits as well as a direct effect.

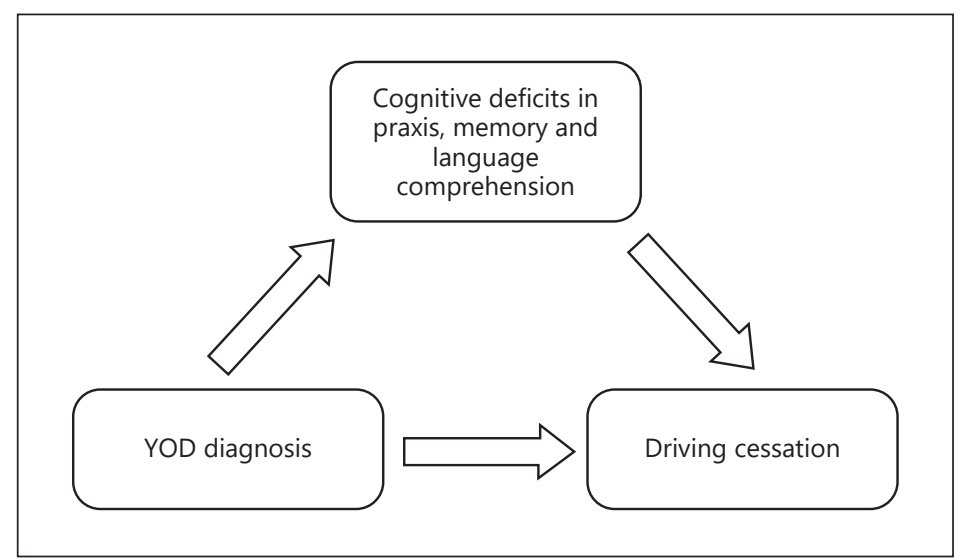

cessation with history of head injury $\left(p=0.098, \chi^{2}(1)=2.74\right)$, alcohol use $\left(p=0.216, \chi^{2}(1)=\right.$ $8.31)$, current smoking $\left(0.554, \chi^{2}(1)=4.923\right)$, presence of depressive symptoms $(p=0.061$, $\left.\chi^{2}(1)=3.498\right)$ or anxiety symptoms $\left(p=0.137, \chi^{2}(1)=5.53\right)$.

Regression analysis showed that YOD diagnosis (for the whole group), female gender (for the YOD group), and total CAMCOG scores (for both YOD and whole group) were significantly 
Table 3. Mediation analysis investigating the association of variables with driving cessation mediated by various cognitive deficits

\begin{tabular}{|c|c|c|c|c|c|c|}
\hline $\begin{array}{l}\text { Direct effect of } \\
\text { YOD diagnosis } \\
\text { OR }(95 \% \mathrm{CI})\end{array}$ & $p$ value & & $\begin{array}{l}\text { Indirect effect } \\
\text { OR }(95 \% \mathrm{CI})\end{array}$ & $p$ value & $\begin{array}{l}\text { Total effect of } \\
\text { dementia diagnosis } \\
\text { OR }(95 \% \mathrm{CI})\end{array}$ & $p$ value \\
\hline \multirow[t]{3}{*}{$\begin{array}{l}0.75 \\
(-0.0444 \text { to } 1.5496)\end{array}$} & 0.064 & Total comprehension & $\begin{array}{l}-0.59 \\
(-1.229 \text { to } 0.119)\end{array}$ & $0.024^{*}$ & $\begin{array}{l}1.19 \\
(0.570 \text { to } 1.814)\end{array}$ & $0.000^{* *}$ \\
\hline & & Total remote memory & $\begin{array}{l}0.31 \\
(0.064 \text { to } 0.667)\end{array}$ & 0.052 & & \\
\hline & & Total praxis & $\begin{array}{l}0.75 \\
(0.183 \text { to } 1.400)\end{array}$ & $0.009^{* *}$ & & \\
\hline
\end{tabular}

Natural direct effect: YOD diagnosis $\rightarrow$ outcome. Natural indirect effect: YOD diagnosis $\rightarrow$ cognition $\rightarrow$ outcome. Total effect: combined natural direct and natural indirect effect. OR, odds ratio. ${ }^{*} p<0.05 ;{ }^{* *} p<0.01$.

associated and predictors of driving cessation (Table 1, model 1). Amongst the CAMCOG subscale scores, impairment of comprehension, remote memory and praxis predicted driving cessation in a binary logistic regression analysis (Table 1, model 2). Mediation analysis revealed that the association between YOD diagnosis and driving cessation was partially mediated by deficits in praxis and less impaired comprehension (Table 3). This was indicated by a significant natural indirect effect of the mediated pathway (Fig. 1) for driving cessation. The effect of mediation was greatest for praxis $(0.7536,95 \%$ CI $0.1834-1.401, p=$ $0.0099)$ towards the total effect of YOD diagnosis $(1.1925,95 \%$ CI $0.5703-1.8147, p=0.0002)$ (Table 3).

\section{Discussion}

To our knowledge, this is the first study to examine the prevalence of driving cessation in younger people with dementia compared to people presenting with CIOC, under the age of 65 years. We found a higher prevalence of driving cessation in people with dementia. The overall prevalence of driving cessation in patients with YOD was $41 \%$. Most of them stopped driving voluntarily while others stopped following advice from a clinician. Women were more likely to stop driving voluntarily than men. This is in keeping with a recent meta-analysis of 9 cross-sectional studies which indicated a more than twofold higher prevalence of driving cessation in older women with and without dementia [6]. In a longitudinal study in above 65 -year-old patients, seen for 2 years pre-dementia and then followed up to 10 years, authors found that a total of $45 \%$ of men and $74 \%$ of women had already ceased driving at dementia diagnosis and the probability of cessation within 3 years after diagnosis was similar between men and women [18]. Another recent longitudinal study which followed up 247 elderly dementia patients over a 3-year period has also reported female gender as a predictor of driving cessation [19].

Explanations suggested for cessation of driving in older women have been: less driving experience explaining more frequently experienced traffic-related stress and avoidance [20]; less likely to engage in risk-taking behaviours whilst driving [21]; drive less frequently [22]; and more likely to self-regulate their driving [23]. A lower sense of confidence while driving among older women compared to older men has been said to potentially lead to higher rates of driving cessation [24, 25]. Similar reasons may explain driving cessation 
among women in our younger cohort. Women may also be more cautious and more likely to be persuaded to stop driving by family and professionals. On the other hand, men might feel more competent, fear losing independence and may experience more shame in admitting their inability to drive, and therefore may be less likely to cease driving. Qualitative studies have suggested that men may be more likely to view their vehicle as an integral part of their identity and social status and therefore continue to drive to maintain a sense of independence [26].

It is known that driving impairment increases as dementia progresses, and that age might play a pivotal role, as with increasing age most cognitive functions tend to decline $[4,27,28]$. Nonetheless, our study in relatively younger people demonstrates that dementia itself is likely to have an impact on the cognitive skills required for driving. The task of driving engages many cognitive domains: visuospatial abilities, attention, memory, and executive functions. Evidence suggests that as cognitive functions start to deteriorate, driving ability also declines [29]. Amongst the cognitive deficits, visuospatial skills and attention have been found as significant predictors for driving impairment in people with later-life dementia [29, 30]. Deficits in visuospatial impairment, disordered attention, reduced processing of visual motion cues, and overall cognitive decline has predicted unsafe behaviour and crashes [21, 30-32]. Performance on standardized tests of visual perception, processing, attention, verbal and visual memory, executive functions, and visuoconstructional abilities has been correlated with the landmark and traffic sign identification task in patients with mild Alzheimer disease compared to neurologically normal controls [33].

To our knowledge, this is the first study to have systematically investigated cognitive domains that may underpin the association between driving cessation and dementia. We demonstrated that deficits in praxis are a significant predictor for driving cessation in people with YOD. Tests for praxis (visuospatial functions) within the CAMCOG included copying and drawing, writing spontaneously and to dictation, ideational and ideomotor tasks. It is not surprising that visuospatial functions, which have been reported to be more impaired in patients with YOD [34], were significantly impaired in our study cohort and were also the most significant mediator for driving cessation. These results are also consistent with independent evidence that female gender and increasing impairment in constructional abilities were significantly associated with driving cessation in late-onset dementia [35]. In addition, our study showed better comprehension-predicted driving cessation, which implies that people with less impaired comprehension, who were more aware of their inabilities, stopped driving. Tests for comprehension within the CAMCOG included motor response and verbal response to instructions and reading comprehension.

The main limitation of the present study lies in the lack of information on driving status for all the patients who attended the YPMS. However, the sensitivity analysis showed that the patients with missing driving data did not differ in their cognitive scores and there were more women in this group compared to the group with driving information; therefore, our study finding that women were more likely to cease driving and voluntarily than men could be an underestimate. Also, care should be taken in interpreting findings from mediation analysis owing to the possibility of unmeasured confounding and temporal ambiguity between the mediator and driving cessation. Another limitation was that there were no details as to the extent the decision to stop driving was self-imposed as opposed to being influenced by caregivers or about the specific difficulties in driving. Nevertheless, the current cohort provides valuable insight into the prevalence and factors affecting driving cessation in younger people with cognitive impairment with and without dementia. Further research in this field is warranted to explore the perspective of the drivers and their reasons for termination; this could help to distinguish between those who are actually impaired and who might just modify their behaviour as a result of a diagnosis of dementia. 
The findings of this study, despite the modest sample size and need for replication, have important potential clinical implications. Impairment of certain cognitive domains such as praxis (visuospatial skills) in people with dementia affects driving ability and cessation. A recent guideline on driving and dementia says knowledge of key elements that increase driving risk will help clinicians to have an informed discussion with patients about whether or not it is sensible for them to continue driving [2]. More research and longitudinal studies are required to determine driving competences of YOD people using driving assessment tools and batteries of cognitive tests.

\section{Conclusion}

This is the first study, to our knowledge, that has investigated and demonstrated that the prevalence of driving cessation in people under 65 years of age with cognitive impairment is higher in those with dementia compared to those without dementia. Women are more likely to stop driving voluntarily, even in the younger cohort. It also provides evidence that the relationship between YOD and driving cessation may be in part mediated through greater impairment in visuospatial skills (praxis). While further studies in larger samples are needed to confirm these findings, these results nevertheless suggest that performance in these cognitive domains may help clinicians assess driving ability and counsel patients and their families.

\section{Disclosure Statement}

The authors report no conflicts of interest.

\section{References}

1 Carr DB, O’Neill D: Mobility and safety issues in drivers with dementia. Int Psychogeriatr 2015;27:1613-1622.

-2 Allan CL, Behrman S, Baruch N, Ebmeier KP: Driving and dementia: a clinical update for mental health professionals. Evid Based Ment Health 2016;19:110-113.

-3 Silva MT, Laks J, Engelhardt E: Neuropsychological tests and driving in dementia: a review of the recent literature. Rev Assoc Med Bras (1992) 2009;55:484-488.

4 Herrmann N, Rapoport MJ, Sambrook R, Hebert R, McCracken P, Robillard A: Predictors of driving cessation in mild-to-moderate dementia. CMAJ 2006;175:591-595.

5 Breen DA, Breen DP, Moore JW, Breen PA, O’Neill D: Driving and dementia. BMJ 2007;334:1365-1369.

6 Baines N, Au B, Rapoport MJ, Naglie G, Tierney MC: Meta-analysis of driving cessation and dementia: does sex matter? J Gerontol B Psychol Sci Soc Sci 2016, Epub ahead of print.

7 Talbot A, Bruce I, Cunningham CJ, Coen RF, Lawlor BA, Coakley D, et al: Driving cessation in patients attending a memory clinic. Age Ageing 2005;34:363-368.

-8 Yamin S, Stinchcombe A, Gagnon S: Deficits in attention and visual processing but not global cognition predict simulated driving errors in drivers diagnosed with mild Alzheimer's disease. Am J Alzheimers Dis Other Demen 2016;31:351-360.

-9 Adler G, Kuskowski M: Driving cessation in older men with dementia. Alzheimer Dis Assoc Disord 2003;17: 68-71.

10 Prince M, Knapp M, Guerchet M, McCrone P, Prina M, Comas-Herrera A, et al: Dementia UK. London, Alzheimer's Society UK, 2014.

11 Harris PB: The perspective of younger people with dementia: still an overlooked population. Soc Work Ment Health 2004;2:17-36.

12 World Health Organization: The ICD-10 Classification of Mental and Behavioural Disorders: Diagnostic Criteria for Research. Geneva, World Health Organization, 1993.

13 Folstein MF, Folstein SE, McHugh PR: "Mini-mental state". A practical method for grading the cognitive state of patients for the clinician. J Psychiatr Res 1975;12:189-198. 
Velayudhan et al.: Driving Cessation in Young-Onset Dementia

14 Huppert FA, Brayne C, Gill C, Paykel ES, Beardsall L: CAMCOG - a concise neuropsychological test to assist dementia diagnosis: socio-demographic determinants in an elderly population sample. Br J Clin Psychol 1995; 34:529-541.

15 Baron RM, Kenny DA: The moderator-mediator variable distinction in social psychological research: conceptual, strategic, and statistical considerations. J Pers Soc Psychol 1986;51:1173-1182.

16 Hayes AF, Matthes J: Computational procedures for probing interactions in OLS and logistic regression: SPSS and SAS implementations. Behav Res Methods 2009;41:924-936.

17 Hayes AF, Preacher KJ: Statistical mediation analysis with a multicategorical independent variable. Br J Math Stat Psychol 2014;67:451-470.

18 Marie Dit Asse L, Fabrigoule C, Helmer C, Laumon B, Berr C, Rouaud O, et al: Gender effect on driving cessation in pre-dementia and dementia phases: results of the 3C population-based study. Int J Geriatr Psychiatry 2017; 32:1049-1058.

19 Connors MH, Ames D, Woodward M, Brodaty H: Predictors of driving cessation in dementia: baseline characteristics and trajectories of disease progression. Alzheimer Dis Assoc Disord 2018;32:57-61.

20 Hakamies-Blomqvist L, Wahlstrom B: Why do older drivers give up driving? Accid Anal Prev 1998;30:305512.

21 Brown LB, Ott BR: Driving and dementia: a review of the literature. J Geriatr Psychiatry Neurol 2004;17:232240.

-22 Ross LA, Clay OJ, Edwards JD, Ball KK, Wadley VG, Vance DE, et al: Do older drivers at-risk for crashes modify their driving over time? J Gerontol B Psychol Sci Soc Sci 2009;64:163-170.

23 Wong IY, Smith SS, Sullivan KA: Psychosocial factors significantly predict driving self-regulation in Australian older adults. Australas J Ageing 2016;35:133-138.

-24 Lafont S, Laumon B, Helmer C, Dartigues JF, Fabrigoule C: Driving cessation and self-reported car crashes in older drivers: the impact of cognitive impairment and dementia in a population-based study. J Geriatr Psychiatry Neurol 2008;21:171-182.

25 D'Ambrosio LA, Donorfio LK, Coughlin JF, Mohyde M, Meyer J: Gender differences in self-regulation patterns and attitudes toward driving among older adults. J Women Aging 2008;20:265-282.

26 Musselwhite CBA, Shergold I: Examining the process of driving cessation in later life. Eur J Ageing 2013;10: 89-100.

27 Ott BR, Heindel WC, Papandonatos GD, Festa EK, Davis JD, Daiello LA, et al: A longitudinal study of drivers with Alzheimer disease. Neurology 2008;70:1171-1178.

28 Duchek JM, Carr DB, Hunt L, Roe CM, Xiong C, Shah K, et al: Longitudinal driving performance in early-stage dementia of the Alzheimer type. J Am Geriatr Soc 2003;51:1342-1347.

29 Reger MA, Welsh RK, Watson G, Cholerton B, Baker LD, Craft S: The relationship between neuropsychological functioning and driving ability in dementia: a meta-analysis. Neuropsychology 2004;18:85.

30 Anderson SW, Rizzo M, Shi Q, Uc EY, Dawson JD (eds): Cognitive Abilities Related to Driving Performance in a Simulator and Crashing on the Road. 3rd Int Driving Symp Hum Factors Driver Assess Training Vehicle Design, Rockport, 2005.

31 Ball K, Owsley C, Sloane ME, Roenker DL, Bruni JR: Visual attention problems as a predictor of vehicle crashes in older drivers. Invest Ophthalmol Vis Sci 1993;34:3110-3123.

-32 Rizzo M, McGehee DV, Dawson JD, Anderson SN: Simulated car crashes at intersections in drivers with Alzheimer disease. Alzheimer Dis Assoc Disord 2001;15:10-20.

-33 Uc EY, Rizzo M, Anderson SW, Shi Q, Dawson JD: Driver landmark and traffic sign identification in early Alzheimer's disease. J Neurol Neurosurg Psychiatry 2005;76:764-768.

34 Mendez MF: The accurate diagnosis of early-onset dementia. Int J Psychiatry Med 2006;36:401-412.

-35 Seiler S, Schmidt H, Lechner A, Benke T, Sanin G, Ransmayr G, et al: Driving cessation and dementia: results of the prospective registry on dementia in Austria (PRODEM). PLoS One 2012;7:e52710. 